\title{
A study to assess the effectiveness of initiation of breast feeding during third stage of labour among mothers on their physiological parameters at selected sub-divisional Hospital in West Bengal
}

\author{
Jyotsna Bag, Sima De* \\ Clinical Instructor, College of Nursing, National Medical College Hospital, Kolkata, West Bengal, India
}

Received: 02 November 2020

Revised: 10 December 2020

Accepted: 11 December 2020

*Correspondence:

Dr. Sima De,

E-mail: simade1967@gmail.com

Copyright: $\odot$ the author(s), publisher and licensee Medip Academy. This is an open-access article distributed under the terms of the Creative Commons Attribution Non-Commercial License, which permits unrestricted non-commercial use, distribution, and reproduction in any medium, provided the original work is properly cited.

\section{ABSTRACT}

Background: There is paucity of Indian literature regarding effect of early breast feeding in subsequent course of labour. So, this study was undertaken to find out the effectiveness of early initiation of breast feeding during third stage of labour on the duration of labour, amount of blood loss during labour and nature of placental expulsion, along with the changes in vital signs during second and third stages of labour among mothers of both experimental and control groups.

Methods: A quasi experimental post-test only control group study design was adopted. The conceptual framework for the study was based on general system model. Non-probability purposive sampling technique was used to select 20 intra-natal mothers and 10 mothers were randomly assigned to experimental group and another 10 mothers were randomly assigned to the control group. A structured interview schedule, observation checklist on progress of $1^{\text {st }}, 2^{\text {nd }}$, and $3^{\text {rd }}$ stages of labour, measurement of blood loss and measurement of vital signs were used to collect data after establishing validity and reliability of the tools.

Results: The finding of the study revealed that there was significant difference in duration of $3^{\text {rd }}$ stage of labour, $t$ $(18)=5.237$ at 0.05 level and blood loss during $3^{\text {rd }}$ and $4^{\text {th }}$ stage of labour, a t (18)=3.95 at 0.05 level. There was true difference in pulse rate but not the respiration rate and blood pressure.

Conclusions: Initiation of breast feeding during third stage of labour is effective in reducing maternal morbidity and mortality.

Keywords: Blood loss, Breast feeding, Placental expulsion, Third and fourth stage of labour

\section{INTRODUCTION}

Labour and delivery management may affect breastfeeding initiation in several ways. Early breastfeeding may also change the progress of labour, especially the third stage of labour. ${ }^{1}$ Breastfeeding provides health, nutritional, immunologic, developmental, psychological, social, economic, and environmental benefits for infants. Breastfeeding has also important implications for women's health, and increasing research supports the benefit for women who breastfeed. ${ }^{2}$ The third stage of labour is the part of labour from the birth of the baby until the placenta and fetal membranes are delivered. After 30 minutes, the third stage of labour is considered to be prolonged, indicating a potential problem. After the uterus has been emptied and the placenta has been delivered, the primary mechanism by which bleeding control is achieved at the placental site is vasoconstriction produced by a well-contracted myometrium. The amount of blood lost depends on how quickly this occurs. If the uterus is atonic and does not contract normally, the blood vessels at the placental site do not adequately constrict and severe bleeding results. Postpartum haemorrhage as a consequence of uterine 
atony represents a leading cause of maternal morbidity and mortality and generally occurs during the third and fourth stage of labour. For this reason, the hour immediately after delivery of the placenta is often referred to as the fourth stage of labor. ${ }^{3}$ Breastfeeding is clearly enhanced by keeping mothers and infants together. This starts right at birth; the first feed happens soonest and most successfully if new-borns stay skin-toskin with mothers beginning immediately after birth. New-borns recognize the smell of their mothers' breasts and root toward it. If left alone, skin-to-skin, infants can find their way to the breast and attach for sucking. Much of the interaction that goes on between any two people is non-verbal. Early mother-infant attachment has been shown to have a lasting effect on interactions between the pair and on the child's later development and well-being via increased breastfeeding period. ${ }^{4}$ Mother-baby bonding is enhanced by breastfeeding. ${ }^{5}$

Initiating breastfeeding within one hour of birth was one of the ten steps to successful breastfeeding on which the BFHI was based and launched in 1992. Step 4 was, "help mothers initiate breastfeeding within a half-hour of birth'. Mothers in the maternity ward who have had normal vaginal deliveries should confirm that within a half-hour of birth they were given their babies to hold with skin contact, for at least 30 minutes, and offered help by a staff member to initiate breastfeeding. At least $50 \%$ of mothers who have had caesarean deliveries should confirm that within a half-hour of being able to respond, they were given their babies to hold with skin contact (The Global Criteria for the WHO/UNICEF Baby Friendly Hospital Initiative, 1992)". There is sufficient scientific evidence to support the step $4 .^{5}$

The objectives of the study were: 1) to assess the effectiveness of initiation of breast feeding on the duration of third stage of labour, amount of blood loss during third and fourth stages of labour, nature of placental expulsion among mothers in both experimental and control groups; 2) to compare the duration of third stage of labour, amount of blood loss during third and fourth stages of labour, nature of placental expulsion among mothers in both experimental and control groups; 3 ) to identify the vital signs of mothers during second stage and third stages of labour; 4) to compare the changes of vital signs during second and third stages of labour among mothers of both experimental and control groups.

\section{METHODS}

The study type was quasi-experimental in approach, and the design adopted was post-test only control group design. The study was conducted at Canning Sub divisional Hospital, Dist-South 24 Parganas, West Bengal, India. The study was done from 27 December 2010 to 08 January 2011. The study population were 20 normal intra-natal mothers, who were admitted in labour ward.

\section{Selection criteria}

Normal intra-natal mothers; primi and multi gravida women between 19- and 30-years age with true labour pain; 3.37-40 weeks of gestation without any complication; who were willing to initiate breast feeding; mother who were in need of episiotomy.

The experimental group with 10 subjects-initiated breast feeding during third stage of labour and the control group with 10 subjects-initiated breasts feeding after third stage of labour.

\section{Procedure}

Samples were collected by non-probability purposive sampling and randomly assigned into two groups (experimental and control groups) in 1:1 ratio. First one was selected as experimental group and second one as control group. After getting formal permission from the respondents, self-introduction and rapport establishment with the subjects were done. Then face to face interview was taken about their background data. Progress of normal labour during the first stage, second stage, duration of third stage and nature of expulsion of placenta were noted. Amount of blood loss during third and fourth stage of labour was measured by use of soakage pads \{measured pad weight before and after use by digital weighing machine and $1 \mathrm{gm}$ was considered as $1 \mathrm{ml}$ ). Vital signs i.e. pulse rate, respiration rate was counted and blood pressure was measured by sphygmomanometer and mean arterial pressure was calculated.

Ethical approval was taken for the study from appropriate authority prior to the study.

\section{Statistical analysis}

The data analysis was planned to include descriptive and inferential statistics. The following plan of data analysis was developed: 1) Frequency, percentage distribution of personal characteristics in terms of background data. 2) Mean, mean difference and t test showing difference of duration of third stage of labour between experimental and control group. 3) Mean, mean difference test showing amount of blood loss during third and fourth stage of labour between experimental and control group. 4) Frequency, percentage distribution of nature of expulsion of placenta between experimental and control group. 5) Mean, mean differenceand $t$ test for showing the difference of vital signs during second andthird stage of labour between experimental and control group.

\section{RESULTS}

\section{Findings related to personal demographic characteristics of the participants}

There was an association between the personal characteristics of two groups. 
Most of the women (65\%) were in the age group of 19 22 years and $80 \%$ of them was Hindu. $95 \%$ women were housewife and he major subject's (80\%) family monthly incomes were in the range of Rs. 2000 to 4000 . Majority of subjects $(45 \%)$ had primary level of education. So, findings revealed that both groups are homogenous and matched in terms of personal characteristics (Table 1).

Table 1: Frequency and percentage distribution of intra-natal mothers by religion, occupation and monthly income of experimental and control groups ( $\mathrm{N}=20)$.

\begin{tabular}{|c|c|c|c|c|c|c|c|}
\hline \multirow{2}{*}{\multicolumn{2}{|c|}{$\begin{array}{l}\text { Sample } \\
\text { characteristics }\end{array}$}} & \multicolumn{2}{|c|}{ Exp. group } & \multicolumn{2}{|c|}{$\begin{array}{l}\text { Control } \\
\text { group }\end{array}$} & \multicolumn{2}{|c|}{ Total } \\
\hline & & f & $\%$ & f & $\%$ & f & $\%$ \\
\hline \multirow{2}{*}{ Religion } & Hindu & 7 & 35 & 9 & 45 & 16 & 80 \\
\hline & Muslim & 3 & 15 & 1 & 5 & 4 & 20 \\
\hline \multirow{2}{*}{ Occupation } & Housewife & 10 & 50 & 9 & 45 & 19 & 95 \\
\hline & Service & 0 & 0 & 1 & 5 & 1 & 5 \\
\hline \multirow{4}{*}{$\begin{array}{l}\text { Monthly } \\
\text { family } \\
\text { income }\end{array}$} & $2000-4000$ & 10 & 50 & 6 & 30 & 16 & 80 \\
\hline & $4001-6000$ & 0 & 0 & 2 & 10 & 2 & 10 \\
\hline & $6001-8000$ & 0 & 0 & 0 & 0 & 0 & 0 \\
\hline & $\begin{array}{l}\text { More than } \\
8000\end{array}$ & 0 & 0 & 2 & 10 & 2 & 10 \\
\hline
\end{tabular}

Findings related to duration of third stage of labour between experimental and control group

Mean score value of duration of third stage of labour was shorter in experimental group than control group $(\mathrm{MD}=3.2)$. The difference in duration was truly significant. ("t" value was 5.237 at df-18 p<0.05) (Table 2).

Table 2: $t$ value of total duration of third stage of labour scores computed between experimental and control group $(n=20)$.

\begin{tabular}{|lllll|}
\hline Group & Mean & $\mathbf{M}_{\mathrm{p}}$ & $\mathrm{SD}$ & $\mathrm{t}$ \\
\hline Experimental & 4.8 & 3.2 & 1.16 & -3.32 \\
\hline Control & 8 & & 1.41 & \\
\hline
\end{tabular}

t $0.05(18)=2.10 ; p<0.05$ Significant

Findings related to blood loss during third stage and fourth stage of labour between experimental and control group (Table 3).

Table 3: $t$ value of total amount of blood loss scores computed between experimental and control group $(\mathbf{n}=20)$.

\begin{tabular}{|lllll|}
\hline Group & Mean & $\mathbf{M}_{\mathbf{p}}$ & SD & $\mathbf{t}$ \\
\hline Experimental & 140 & 43.7 & 16.04 & -5.35 \\
\hline Control & 183.7 & & 29.02 & \\
\hline
\end{tabular}

t $0.05(18)=2.10 ; \mathrm{p}<0.05$ Significant

Mean score of amounts of blood loss was less in experimental group than control group which was statistically significant. ('t' value was 3.95 at df-18 $\mathrm{p}<0.05$.)

Findings related to nature of expulsion of placenta between experimental and control group

Frequency and percentage of nature of placental expulsion shown 30\% mother in experimental group expelled placenta by Schultz method and 30\% mothers of control group expelled placenta by Duncan method (Table 4).

Table 4: Frequency and percentage of method of expulsion of placenta between experimental and control group $(\mathbf{n}=20)$.

\begin{tabular}{|c|c|c|c|c|c|c|}
\hline \multirow{2}{*}{$\begin{array}{l}\text { Method of } \\
\text { placental } \\
\text { expulsion }\end{array}$} & \multicolumn{2}{|c|}{$\begin{array}{l}\text { Experimental } \\
\text { group }\end{array}$} & \multicolumn{2}{|c|}{$\begin{array}{l}\text { Control } \\
\text { group }\end{array}$} & \multicolumn{2}{|c|}{ Total } \\
\hline & f & $\%$ & f & $\%$ & f & $\%$ \\
\hline Duncan & 4 & 20 & 6 & 30 & 10 & 50 \\
\hline Schultz & 6 & 30 & 4 & 20 & 10 & 50 \\
\hline
\end{tabular}

\section{Computed individual mean difference of pulse rate of both groups}

Mean score of pulse rate (individual difference) was higher in experimental group compared to control group and which was statistically significant ( $\mathrm{t}$ value was 4.889 at df-18 p<0.05) (Table 5).

Table 5: Computed individual mean difference of pulse rate of both groups, the mean and SD of individual $M_{D}$, and computed $t$ test with the above mean $(n=20)$.

\begin{tabular}{|lllll|}
\hline Group & Mean & $\mathbf{M}_{\mathbf{p}}$ & $\mathrm{SD}$ & $\mathbf{t}$ \\
\hline Experimental & 26.4 & 13.2 & 7.25 & 4.9 \\
\hline Control & 13.2 & & 3.6 & \\
\hline
\end{tabular}

t $0.05(18)=2.10 ; p<0.05$ Significant

Computed individual mean difference of respiration rate of both groups

Mean score of respiration rate (individual difference) was higher in experimental group compared to control group and which was statistically not significant ( $\mathrm{t}$ value was 1.986 at df-18 p>0.05) (Table 6).

Table 6: Computed individual mean difference of respiration rate of both groups, the mean and SD of individual $M_{D}$, and computed $t$ test with the above mean $(n=20)$.

\begin{tabular}{|lllll|}
\hline Group & Mean & $\mathbf{M p}_{\mathrm{p}}$ & $\mathrm{SD}$ & $\mathrm{t}$ \\
\hline Experimental & 3.4 & 1.5 & 1.85 & 0.81 \\
\hline Control & 1.9 & & 1.3 & \\
\hline
\end{tabular}

t $0.05(18)=2.10 ; \mathrm{p}<0.05$ Significant 


\section{Computed individual mean difference of mean arterial pressure of both groups}

Mean score of mean arterial pressure (individual difference) was higher in experimental group compared to control group and which was statistically not significant (Table 7).

Table 7: Computed individual mean arterial pressure of both groups, the mean and SD of individual MD, and computed $t$ test with the above mean $(n=20)$.

\begin{tabular}{|lllll|}
\hline Group & Mean & $\mathbf{M}_{\mathbf{p}}$ & SD & $\mathbf{t}$ \\
\hline Experimental & 10.9 & 2 & 3.64 & 0.88 \\
\hline Control & 8.9 & & 5.68 & \\
\hline
\end{tabular}

t $0.05(18)=2.10 ; p<0.05$ Significant

\section{DISCUSSION}

The findings of this present study reveal that early initiation of breast feeding during third stage of labour has shown beneficial effects on duration of third stage of labour, amount of blood loss during third and fourth stages of labour, nature of placental expulsion and stabilization of vital signs i.e. pulse rate, respiration rate and blood pressure. The same findings are reported by several authors such as Sobhy et al and Bilgic et al. ${ }^{6,7}$

All of them also support in various randomized clinical studies with effectiveness of breast feeding with clinical condition like breast feeding and intelligence, breast feeding and blood loss, breast feeding and duration of third stage of labour, breast feeding and maternal and neonatal mortality and morbidity.

The present study reveals that no significant difference was found in the blood pressure (mean arterial pressure) and respiration rate during second and third stages of labour between experimental and control groups.

The present study showed that duration (time) of third stage of labour was significantly shorter in group who initiated breast feeding during third stage of labour.

It also has been reported by Bilgic et al. The rate of placental delivery at the first 5-10 minutes of the third stage was significantly higher $(83.3 \%$ versus $16.7 \%)$ in the early-breastfeeding group $(\mathrm{p}<0.05)$. This rate in the group of mothers who prefer to feed their infants with early-breastfeeding during first 2-9 minutes was found higher $(92.6 \%$ versus $7.4 \%)$ than those of preferring breastfeeding after more than 10 minutes $(\mathrm{p}<0.05){ }^{7}$

The present study shows that mean score of amounts of blood loss was less in experimental group than control group which was statistically significant (" $t$ " value was 3.95 at df-18 $\mathrm{p}<0.05)$. The finding shows by other researcher who conducted such study.
It also has been reported by Newton et al that mean blood loss on the delivery table for all patients was $339 \mathrm{ml}^{8}$ There was wide individual variation. Primi-para lost significantly more blood than multi-paras. Women who had delivered 5 or more children previously lost significantly more blood than women who had delivered 1-4 children before. Multi-paras who had received an episiotomy lost significantly more blood than multi-paras who had sustained neither a laceration nor an episiotomy. The performance of an episiotomy increased blood loss in multi-paras by a mean amount of $153 \mathrm{ml}$.

Razvi et al did a study to compare between visual estimation and laboratory determination of blood loss during the third stage of labour. ${ }^{9}$ A prospective study was conducted to compare the accuracy of visual estimation of blood loss (EBL) at delivery with laboratory determination of measured blood loss (MBL). It showed that EBL tends to be clouded by the conventional teaching that blood loss at delivery is usually between 200 and $300 \mathrm{ml}$. Women with MBL up to $150 \mathrm{ml}$ were overestimated and the best correlation was in women with MBL between 150 to $300 \mathrm{ml}$. There was a tendency to underestimate blood loss when the MBL was between 301 to $500 \mathrm{ml}$. of the 9 women with a primary postpartum haemorrhage, only one was correctly diagnosed as such and 3 women were estimated to have blood losses of at least $500 \mathrm{ml}$ but the measured blood losses were all lower. It was concluded that visual estimation of blood loss was inaccurate, especially at the extremes of MBL and that primary postpartum haemorrhage was not detected by visual estimation of blood loss, unless there were associated signs of homodynamic instability.

The present study shows the frequency and percentage of nature of placental expulsion. About 30\% mother in experimental group expelled placenta by Schultz method and 30\% mothers expelled placenta by Duncan method.

\section{CONCLUSION}

Based on this scientific evidence it is concluded that initiation of breast feeding during third stage of labour is effective. It is shortening the duration of third stage of labour. Breast feeding helps to reduce blood loss during intra-partum and post-partum period. Breast feeding is effective on stabilization of pulse rate during third stage of labour.

\section{ACKNOWLEDGMENTS}

Authors would like to thank Superintendent, Canning SD hospital, West Bengal and CMOH, South 24 Parganas, West Bengal for their kind permission to do the study.

Funding: No funding sources

Conflict of interest: None declared

Ethical approval: The study was approved by the Institutional Ethics Committee 


\section{REFERENCES}

1. Widstrom AM, Wahlberg V, Matthiesen AS, Eneroth $\mathrm{P}$, Uvnas-Moberg K, Werner S, et.al. Short-term effects of early suckling and touch of the nipple on maternal behaviour. Early Hum Dev. 1990;21:15363.

2. Montgomery AM. Breastfeeding and postpartum maternal care. Prim Care. 2000;27:237-50.

3. Moreland J, Coombs J. Promoting and supporting breast-feeding. Am Fam Phys. 2000;61(7):2093-104.

4. Febo M. Early initiation of breast feeding and its benefit in rural Egypt. Int breastfeed $\mathrm{J}$. 2007;104(1):3-4.

5. Evidence for the ten steps to successful breastfeeding. Family and Reproductive Health, Division of Child Health and Development. World Health Organization: Geneva; 1998.

6. Sobhy SI, Mohame NA. The effect of early initiation of breast feeding on the amount of vaginal blood loss during the fourth stage of labor. J Egypt Public Health Assoc. 2004;79(1-2):1-12.

7. Haider R, Rasheed S, Sanghvi TG, Hassan N, Pachon H, Islam S, et al. Breastfeeding in infancy: identifying the program-relevant issues in Bangladesh. Int Breastfeed J. 2010;5:21

8. Newton M, Mosey LM, Egli GE, Gifford WB, Hull CT. Blood loss during and immediately after delivery. Obstet Gynecol. 1961;17(1):9-18.

9. Razvi K, Chua S, Arulkumaran S, Ratnam SS. Comparisons between visual estimation and laboratory determination of blood loss during the third stage of labour. A N Z J Obstet Gynecol. 1996;36(2):152-4.

Cite this article as: Bag J, De S. A study to assess the effectiveness of initiation of breast feeding during third stage of labour among mothers on their physiological parameters at selected sub-divisional Hospital in West Bengal. Int J Reprod Contracept Obstet Gynecol 2021;10:285-9. 